\title{
Regional variability in landscape effects on forest bird communities
}

\author{
Rebecca Spake - Masashi Soga $\cdot$ Kazuhiro Kawamura • Robert S. Cooke • \\ Yuichi Yamaura $\cdot$ Felix Eigenbrod
}

Received: 20 December 2019/Accepted: 25 March 2020/Published online: 5 April 2020

(C) The Author(s) 2020

\begin{abstract}
Context Functional responses to landscape heterogeneity are context-dependent, hampering the transferability of landscape-scale conservation initiatives. Japan provides a unique opportunity to test for regional modification of landscape effects due to its broad temperature gradient, coincident with a gradient of historical disturbance intensity.
\end{abstract}

Electronic supplementary material The online version of this article (doi:https://doi.org/10.1007/s10980-020-01005-9) contains supplementary material, which is available to authorized users.

R. Spake $(\bowtie) \cdot$ R. S. Cooke · F. Eigenbrod Geography and Environmental Science, University of Southampton, Building 44, Southampton SO17 1BJ, UK e-mail: R.Spake@soton.ac.uk

\section{Soga}

Graduate School of Agriculture and Life Science, University of Tokyo, 1-1-1, Yayoi, Bunkyo-ku,

Tokyo 113-8657, Japan

\section{K. Kawamura}

Graduate School of Agriculture, Hokkaido University, Nishi 9, Kita 9, Kita-ku, Sapporo, Hokkaido 060-8589, Japan

\section{R. S. Cooke}

Department of Biological and Environmental Sciences, University of Gothenburg, Box 463, 40530 Göteborg, Sweden
Objectives To quantify and understand how regional contexts modify forest bird community responses to landscape heterogeneity across Japan.

Methods We characterised the functional trait composition and diversity of breeding bird communities from 297 forest sites, and applied a cross-scale analytical framework to explain regional variation in community responses.

Results The effects of landscape diversity, coincident with forest loss, varied in strength and even direction across the temperature gradient. Cool regions of Japan with highly forested, homogeneous landscapes supported bird communities dominated by forest specialists: those with narrow habitat breadths and insectivorous diets. Warmer regions comprised

\section{R. S. Cooke}

Gothenburg Global Biodiversity Centre, Box 461,

40530 Göteborg, Sweden

\section{Y. Yamaura}

Shikoku Research Center, Forestry and Forest Products

Research Institute, 2-915 Asakuranishi, Kochi,

Kochi 780-8077, Japan

\section{Y. Yamaura}

Fenner School of Environment and Society, Australian National University, Canberra, ACT 2601, Australia 
communities dominated by generalists with wider habitat breadths, even in contiguous, highly forested landscapes. Heterogeneous landscapes selected for generalists, and only promoted functional trait diversity in cool regions where both specialists and generalists can be supplied by a diverse regional pool. Conclusions Our results provide evidence that regional variation in trait responses to landscape heterogeneity — driven by past environmental filtering and broad-scale climates-leads to differential community responses across Japan. Future research that seeks a nuanced understanding of the regional modification of landscape variables will better serve to inform and target real-world conservation efforts.

Keywords Biodiversity - Cross-scale interaction . Diet · Extinction filter · Functional diversity - Habitat breadth · Japan · Landscape heterogeneity · Legacy

\section{Introduction}

Humans have changed landscape pattern and process across most of the terrestrial biosphere (Ellis and Ramankutty 2008; Ellis 2011), yielding significant changes to biodiversity (Newbold et al. 2015). Studies documenting the effects of landscape pattern on biodiversity are increasingly adopting functional, rather than solely taxonomic perspectives (Laliberté et al. 2010; Coster et al. 2015; Klingbeil and Willig 2016; Vaccaro et al. 2019), by focussing on the morphological, physiological or phenological traits that influence species' abilities to acquire resources, disperse and persist (Violle et al. 2007). This is because functional rather than taxonomic analyses should hold greater scope for generalisation, especially when comparing different regions with different species pools (McGill et al. 2006; Shipley 2007). However, much idiosyncrasy remains among studies of functional responses to landscape pattern, whereby the relative importance of ecological processes seems to differ from place to place (Rhodes et al. 2008; Morissette et al. 2019), and findings from one study do not necessarily apply to others (Randin et al. 2006; Lessard et al. 2012). Such context-dependency is poorly understood (Shackelford et al. 2016; Jin et al. 2019), hampering the effective transferability of landscape-scale conservation and management policies (Gilroy et al. 2014).

Landscape pattern may be considered as an ecological filter, which selects or excludes species from the regional species pool according to particular traits (Duflot et al. 2014). However, variation amongst regional contexts, as defined by varying climate, productivity, habitat quality and disturbance history, and consequently species pools, could potentially modify the strength and even direction of community responses to landscape pattern (Mayfield et al. 2010; Lessard et al. 2012; Conradi and Kollmann 2016). For example, Morissette et al. (2019) demonstrated regional differences in the responses of several wetland-associated bird species to landscapes varying in boreal forest conversion to agriculture in Canada, likely because of regional differences in forest types and species pools. Historically disturbed regions comprise higher densities of generalists rather than specialists with distinct traits, a result of the greater vulnerability of specialists to environmental change (Clavel et al. 2011). Such functionally homogenous species pools might constrain any potential ecological filtering imposed on the community response to landscape properties. For example, a global metaanalysis of animal density responses to forest patch size found weaker relationships from eastern than western continents (Bender et al. 1998). Eastern continents are likely to have more area-insensitive generalists dominate their regional pools, having had longer histories of large-scale anthropogenic disturbance than western regions (Bender et al. 1998). Similarly, Betts et al. (2019) demonstrated that species inhabiting landscapes with high levels of disturbances over historical (evolutionary) time scales, i.e. subjected to an 'extinction filter' were more resilient to new disturbances, likely because sensitive species have been driven locally extinct or because extant species have adapted to disturbance.

Regional variation in the effects of landscape patterns on communities have been primarily detected through the synthesis of published regional case studies using meta-analysis. Examples include fragmentation effects on nest predation (Chalfoun et al. 2002), habitat amount effects on population densities (Bender et al. 1998; Connor et al. 2000), and edge effects on communities (Ries et al. 2004). Methodological differences between individual studies that comprise the meta-analyses have made attribution 
concerning true regional variation in landscape effects challenging: different studies use different spatial extents, grains and designs (Spake and Doncaster 2017), sample from different ranges of landscape metrics that characterise landscape pattern, and often do not adequately parametrise regional contexts to allow for a mechanistic understanding (Gerstner et al. 2017). Large-scale empirical tests of regional variation in functional responses to landscape pattern, based on standardised sampling, are lacking.

The nation of Japan provides a unique opportunity to test for regional variation in avian community responses to local landscape pattern (Yamaura et al. 2011; Spake et al. 2019b). Around two thirds of Japan is forested, with varying degrees of landscape pattern from forest to agricultural and urban land uses, leading to high variability in landscape-level forest cover, and consequently varying degrees of the diversity of different land cover types. Indeed, forest cover and landscape diversity are inextricably confounded in Japan (Katayama et al. 2014), and we use the term 'landscape heterogeneity' to refer to both processes. The diversity and community composition of birds are both known to be driven by landscape heterogeneity (e.g. Yamaura et al. 2008).

Moreover, a temperature gradient covaries strongly with forest quality and historical land use intensity across Japan (details in Appendix S1), providing the opportunity to test for the gradient's moderation of avian community responses to landscape heterogeneity (Totman 1989; Katayama et al. 2014). Temperature largely determines the relative abundance of tree functional types, with forests increasingly dominated by deciduous broadleaved trees with decreasing temperatures, coinciding with a decrease in evergreen broadleaved trees (Suzuki et al. 2015). Because cooler regions are dominated by broadleaved deciduous trees, their productivity increases rapidly from spring to summer to support greater insect abundance so that they comprise a higher quality food resource during the breeding season than forests in warmer regions (Blondel et al. 1993; Huston and Wolverton 2009; Fujita et al. 2016), as lepidopteran larvae are important food sources for nestlings (Holmes et al. 1986; Huston and Wolverton 2009). Moreover, forests in cooler regions have experienced less historical disturbance than warmer regions, where evergreen broad-leaved forests have been exploited by humans for millennia to support energy-intensive industries such as traditional ironwork and pottery-making (Totman 1989; Fukasawa and Akasaka 2019). Consequently, cooler regions in Japan support relatively rich avian species pools during the breeding season, with a higher proportion of specialists (Yamaura et al. 2011; Katayama et al. 2014). Therefore, across the temperature gradient of Japan, which coincides with past disturbance intensity and productivity, we can expect the effect of landscape heterogeneity on avian functional traits to interact with the temperature gradient and exhibit regional variation (i.e., 'cross-scale interactions'; Peters et al. 2007).

We applied a recently developed framework (Spake et al. 2019a), to test for and quantify cross-scale interactions that drive variability in forest bird community responses (trait composition and diversity) to landscape heterogeneity using a national-scale standardized monitoring dataset. This framework helps to reveal how different regional contexts might constrain or modify the effects of local drivers on a phenomenon in question, allowing an understanding of contextdependence. We were specifically interested in two main questions: (1) How does the distribution and diversity of individual avian functional traits respond to landscape heterogeneity; and (2) is there regional variation in these responses? Decreasing forest amount typically concords with a reduction in food and nesting resources, and habitat quality, due to the intensification of edge effects (Fletcher 2005). Therefore, the dominance of forest specialists, i.e. species that breed only in forest interiors (away from open habitats and edges; Askins 1992; Kurosawa and Askins 2003), and species with insectivorous diets were hypothesised to decline with landscape heterogeneity. We predicted this to manifest to an increase in mean habitat breadth and a decrease in insectivory (Blake 1983; Gray et al. 2007). We predicted this filtering to be weaker in warm, historically disturbed regions where generalists are expected to dominate in even highly forested landscapes (Fig. 1; Bender et al. 1998). Given that cooler regions in Japan have more diverse species pools and comprise higher quality forest (Blondel et al. 1993; Huston and Wolverton 2008), we hypothesised that specialists, which dominate in contiguous landscapes, could also persist in heterogeneous landscapes in addition to generalists (Fujita et al. 2016) within cooler regions, and therefore predicted stronger trait diversity responses to 
Cool region, low historical disturbance, high forest quality
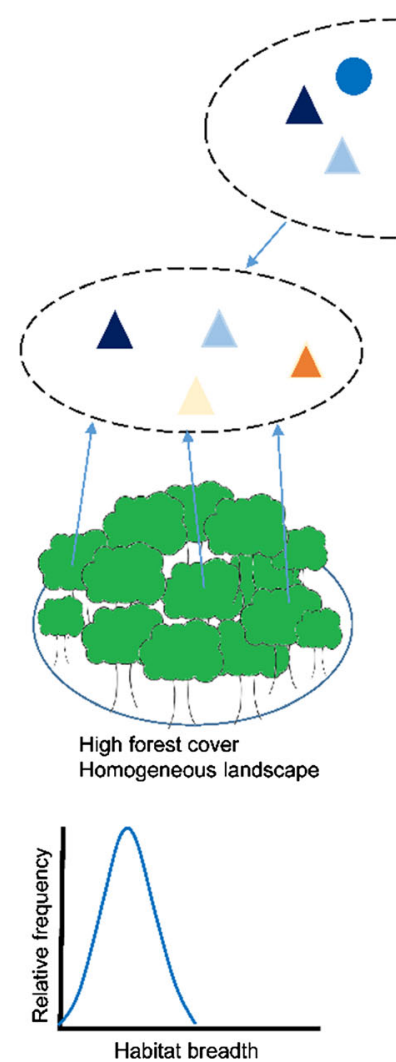

Habitat breadth
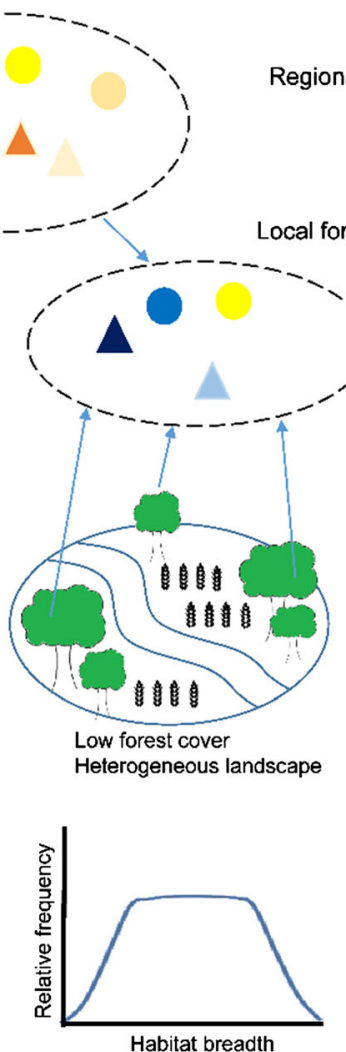

Regional species pools

Warm region, high historical disturbance, low forest quality
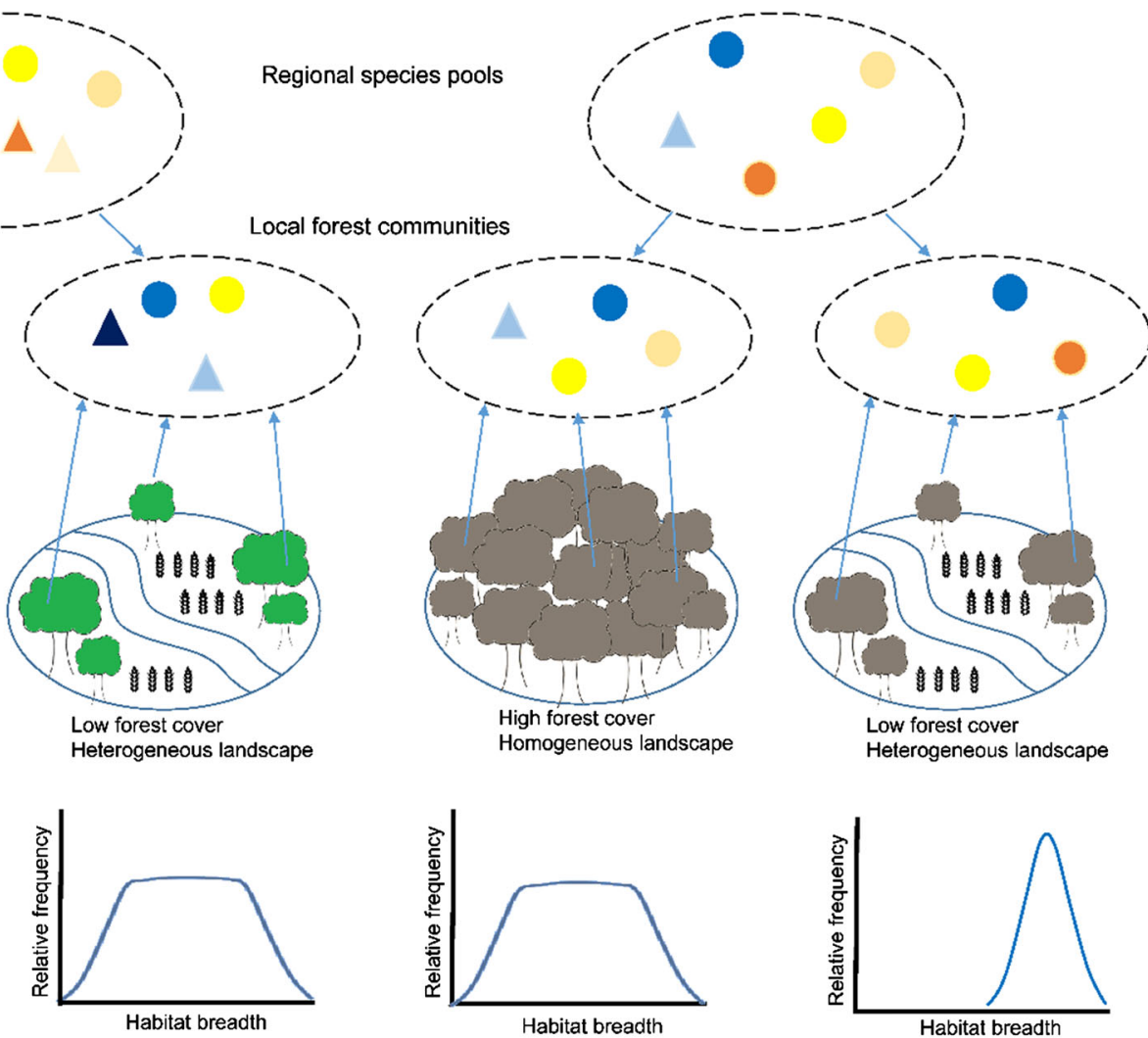

Trait mean
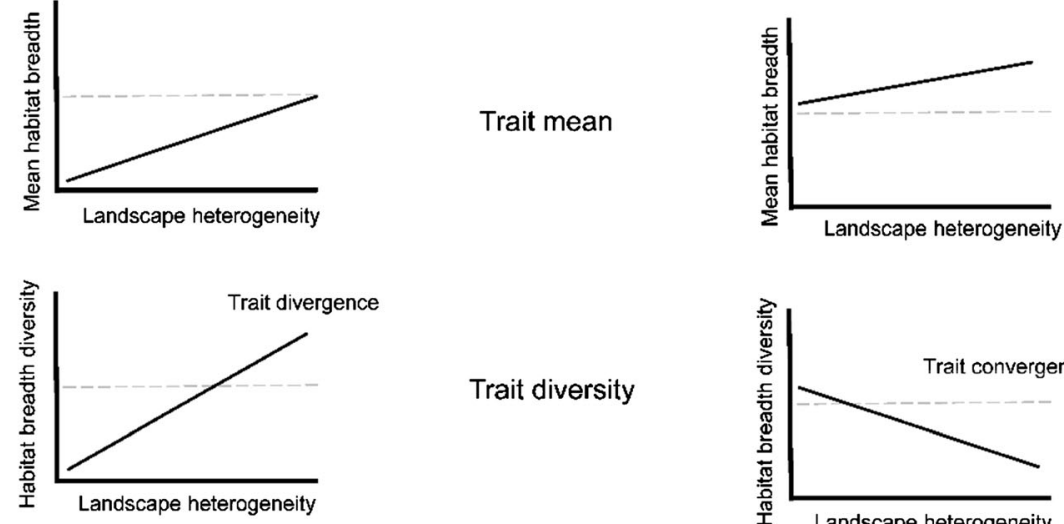

Trait diversity

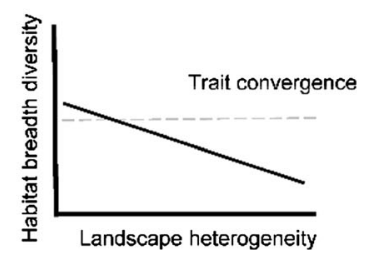

Fig. 1 Hypothesised filtering of regional species pools by landscape heterogeneity in cool (left) and warm (right) regions of Japan, and consequences for functional trait composition of forest bird communities. Circles represent generalist species that utilise multiple habitat types, while varying shapes represent specialists with specific habitat affinities; different colours represent different species. Tree colour represents forest habitat quality (green $=$ high in cooler regions, grey $=$ low in warm regions). In the cool region, low historical disturbance means that a species-rich pool can supply both specialist and generalist species to high quality habitats in diverse landscapes with lower forest cover, in which specialists can persist. In the warm region, a depauperate species pool dominated by generalists means that few specialists can be supported in even highly forested landscapes, and less so in diverse landscapes with lower forest cover. Note that sampling is only from forest habitats 
landscape heterogeneity in cooler regions than in warmer regions.

\section{Methods}

We quantified the effects of environmental drivers on community functional trait means and trait diversity values by comparing observed communities to null models simulating random distributions of traits within communities of a given species richness (Bello et al. 2012; Concepción et al. 2017). We tested for cross-scale interactions between temperature and landscape heterogeneity to identify regional variation in landscape effects on these trait parameters. We modelled variation in temperature as surrogate for variation in historical disturbance intensity, forest quality as a food resource and regional species pools (justified in Appendix S1), because temperature is likely measured with the least error and available across Japan. We discuss the limitations of this approach in the discussion.

\section{Study area: Japan}

We used data on songbird communities sampled at forest sites across Japan. Japan is composed of many islands, with the four largest islands accounting for most of the land area spanning the warm-temperate zone to the boreal zone (approximately $31^{\circ}-45.5^{\circ} \mathrm{N}$, $129.6^{\circ}-145.8^{\circ}$ E). In Japan, $68 \%$ of the land is forested, $40 \%$ of which consists of conifer plantations, and the remainder classed as naturally regenerating following varying degrees of exploitation for raw materials (Yamaura et al. 2012). In addition to forests, agricultural land $(\sim 12 \%)$ and grassland $(\sim 3 \%)$ have long been maintained by human activity, creating heterogeneous mosaic landscapes known as 'satoyama' (Takeuchi 2010). See Appendix S1 for further details of historical disturbance and forest quality variation with temperature across Japan.

Forest breeding songbird abundance data

Songbird abundance data were obtained from the Monitoring Sites 1000 Project, a nationwide monitoring survey of biodiversity across terrestrial and aquatic ecosystems (Ministry of the Environment 2018; Appendix S2). We selected only forest sites because the sampling of other terrestrial habitats (grasslands) was comparatively rare, and to reduce the likelihood of 'detection filtering', whereby functional traits might influence the probability of detecting species during a field survey (Roth et al. 2018) (see discussion). At each site, a survey was conducted every $1-5$ years. Approximately $10 \%$ of sites were surveyed by ornithologists, while the rest were surveyed by citizen scientists, many of whom were members of the Wild Bird Society of Japan (https://www.wbsj.org/en/). Citizen surveyors also received specialist training in species identification both indoors and outdoors at annual training centres located across Japan. These trained surveyors visited each site four times in the breeding season (April to July) and recorded all birds detected. The surveys were conducted on both clear and cloudy days (from 0400 to $0900 \mathrm{~h}$ ), on days without rain or strong winds to minimise variation in detection probability.

In each site, there was a single 1-km transect with five point-count locations, which were $>100$-m apart. Three detection radii were defined during the survey: (i) within 50-m, (ii) between 50- and 200-m, and (iii) over 200-m. Survey ranges from each point overlapped for the larger radii, so we used data from the 50 -m survey radius only to avoid double counting among surveys. Moreover, the use of a 50-m detection radius is recommended in point-count surveys (Ralph et al. 1993; Matsuoka et al. 2014), because it has been shown that detection probability of songbirds can be sufficiently high and comparable within this radius for different species and different habitats (Schieck 1997; Alldredge et al. 2007; Yamaura and Royle 2017).

We used the survey results from 2009 to 2015 because the same survey method (i.e., point census counts) was used in each of these years. First, we took the maximum abundance observed for each species in five point-count locations for each site in each year. We used the maximum number of individuals from four surveys in a single year, based on the assumption that abundance is generally underestimated by point counts, and therefore that the maximum number of birds detected in any visit represents the minimum number at that location (Bibby et al. 2000). Moreover, the maximum, rather than the average was used because averaging values across a breeding season would produce a misleading estimate for species that were not present or not singing during one or more surveys (Miller et al. 2004) and because maximum 
point-counts can better reflect territory abundance than mean point-counts (Toms et al. 2006).

We then took the maximum values of abundance across the available sampling years as the analysis unit, which correlated strongly with the mean abundance among multiple survey years (Appendix S3). This approach was used instead of a mixed-effects modelling framework (with site identified as a random effect), because models can be unstable if sample sizes across groups are highly unbalanced, i.e. if some groups contain very few data (Grueber et al. 2011). Almost half the sites were sampled for one year only (Appendix S3). Our large number of sites with just a single year's data, and therefore number of levels of the random effect with just one observation, would artificially reduce the $95 \%$ confidence intervals (Harrison 2015). Sites outside of the four main islands of the Japanese Archipelago were excluded, due to their very different biogeography, outlying values of climate variables, and to control for island-size effects on regional species pools (Yamaura et al. 2011; Saito et al. 2016; Fukasawa and Akasaka 2019; Kawamura et al. 2019). We also excluded transects for which environmental data (climate and land cover) could not be obtained (Katayama et al. 2014), giving a total of 297 forest sites available for analysis (Appendix S2).

\section{Environmental data}

Climatic variables were available at a $1-\mathrm{km}$ resolution (the Mesh Climate Value 2010 provided by the Meteorological Agency of Japan), and included temperature, rainfall, sunshine duration, and snow depth based on annual averages between 1981 and 2010 (https://nlftp.mlit.go.jp/ksj/index.html [in Japanese]). For temperature, we calculated annual averages for mean temperature, and the mean temperature during the breeding season. We extracted each site's elevation and topographic position index (TPI; the difference between elevation at the site, and the mean elevation within a $100-\mathrm{m}$ radius), using a $30-\mathrm{m}$ resolution global digital elevation model (derived from Shuttle Radar Topography Mission 1 Arc-Second Global data downloaded from https://earthexplorer. usgs.gov). Further details of data sources and processing are given in Appendix S3.
Characterisation of landscape heterogeneity

We were interested in the effect of the landscape heterogeneity on forest bird communities. To characterise landscape heterogeneity (i.e. the conversion of forest to other land uses and so increase in heterogeneity), we calculated the proportional cover of the following land use types in circular buffers surrounding focal sites: forest, grassland, wetland, urban, cropland, using JAXA land cover map available at 30-m resolution for the period 2014-2016 (https:// www.eorc.jaxa.jp/ALOS/lulc/lulc_jindex_v1803.htm [in Japanese]). JAXA classifies land cover using Landsat- 8 surface reflectance data (collection-1) distributed by United States Geological Survey and has an overall accuracy of $82 \%$. We quantified these metrics in circular buffers surrounding the centre of the transects with radii $500-\mathrm{m}, 1-\mathrm{km}, 2-\mathrm{km}, 3-\mathrm{km}$ and $5-\mathrm{km}$. These buffer extents were considered appropriate because they (i) encompass the scale of effect of landscape structure detected in a previous landscape ecological study of bird communities in Japan (Katayama et al. 2014); and because (ii) larger extents reduce both the variability amongst landscapes and potential for non-overlapping independent landscapes (Pasher et al. 2013). All forest sites were located in forested landscapes, ranging from 60 to $100 \%$ within a $2-\mathrm{km}$ radius (Appendix S3). In addition to proportional cover, we also quantified a widely used measure of landscape diversity, the Shannon-Wiener index using the proportional cover of these land uses.

Forest cover and landscape diversity are highly correlated across Japan, as shown by a high degree of collinearity (Spearman's rho $=0.99$ when quantified within a radius of $1-\mathrm{km}$, Appendix S3), making it impossible to distinguish between these components. In our discussion, we use the term 'landscape heterogeneity' to refer to the conversion (and loss) of forest to more diverse, heterogeneous landscapes. We used model selection to identify which metric (forest cover or landscape diversity) explained the greatest variation in the response variables in question (see below).

Functional traits

We analysed variation in the mean and diversity of two functional traits that related to our hypotheses (see introduction). Firstly, a species' habitat breadth is considered a surrogate of the degree of generalism and 
specialism (Luck et al. 2013), and should confer its capacity to adapt to environmental change, especially changes in land cover. The sum of the habitats that birds are able to breed in, including grassland, forest, wetland and agriculture (1-4), was taken from JAVIAN Database (Takagawa et al. 2011). Secondly, we retrieved data on the proportion of diet composed of invertebrates (0-1) from Wilman et al. (2014). Diet type and diet breadth of a species will dictate how they respond to changes in resource availability (i.e., disturbances that impact the resources they consume, such as invertebrate abundance). During the breeding season, forest bird specialists will largely be insectivorous (Luck et al. 2013).

Calculation of bird community composition metrics

In addition to total abundance and species richness at each site, we calculated two trait-based measures of community composition for each functional trait, that are commonly used in functional trait analyses to understand community responses to landscape variables using R package FD (Laliberté et al. 2014):

(1) Community-level weighted means of trait values were calculated as the sum, across all species, of the products of each species' trait value and their relative abundance, divided by the total abundance (Garnier et al. 2004). Calculating the mean trait values of a community allows for the evaluation of the association between trait dominance and environmental drivers (Garnier et al. 2004).

(2) Trait diversity was calculated as Rao's quadratic entropy (Rao 1982), the sum of pairwise distances between species in a community weighted by their relative abundances, with functional distances between species calculated using Gower's distance metric (Laliberte and Legendre 2010). As such, Rao's quadratic entropy expresses the mean distance between two randomly selected individuals in a community and is a measure of dispersion of species in trait space (Fig. 1). It has been widely used to successfully detect trait convergence and divergence of ecological communities in response to environmental drivers (e.g. Bello et al. 2012; Spake et al. 2016). Prior to the calculation of trait mean and diversity values, abundance values were log-transformed (Ribera et al. 2001), and habitat breadth was square-root transformed to improve normality as recommended for trait analyses (Villéger et al. 2008; Blonder et al. 2014).

For the two trait-based measures, we calculated standardised effect sizes (SES; Gotelli and Mccabe 2007), that measure the number of standard deviations (SD) that observed trait mean and trait diversity values $\left(\right.$ TRAIT $_{\text {obs }}$ ) are above or below the mean value of

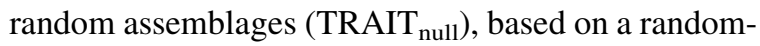
ization of species composition (i.e., independently of differences in species richness). We used the $\mathrm{R}$ package picante (Kembel et al. 2010) to simulate 1000 assemblages, wherein the species composition across all sites was reshuffled at random, while maintaining both the observed species richness and total abundance of each site. SES were calculated as: SES $=\left[\right.$ TRAIT $_{\text {obs }}-\operatorname{mean}\left(\right.$ TRAIT $\left.\left._{\text {null }}\right)\right] /$

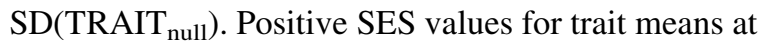
a site are indicative of higher than average trait values, while positive SES for trait diversity reflect trait divergence, where communities are dominated by species with more distinct traits than expected at random. Negative SES values for trait means indicate lower than average trait values, while negative trait diversity SES values indicate trait convergence, with communities dominated by species with more similar traits than expected at random. For brevity, we refer to the standardised effect sizes simply as trait means and trait diversity. We also calculated species richness (total number of bird species at a site) and the Shannon diversity index as taxonomic metrics of diversity.

\section{Statistical analyses}

\section{Statistical modelling of taxonomic and functional diversity metrics}

Generalised linear models were fitted to quantify how richness and abundance and the community-level trait mean and trait diversity values varied with environmental drivers including temperature and landscape heterogeneity variables, and their interactions (Spake et al. 2019a). Models of total abundance and richness values (both comprising count data) were fitted via a generalised linear model with a negative binomial 
distribution and log link function, while normal error distributions and an identity link function were used for individual trait mean and trait diversity values. We created global models that contained the additive main effects of a landscape heterogeneity variable (landscape diversity or forest cover), temperature, rainfall, sunshine duration, elevation and TPI, in addition to an interaction between temperature and the landscape heterogeneity variable as hypothesised, and also rainfall and the landscape heterogeneity variables (see Appendix S4 for details of the global model). We included quadratic or $\log _{10}$ functions of the climatic and landscape variables, respectively, to test for plausible nonlinear relationships. Elevation was $\log _{10}$ transformed to reduce the effect of outliers. Global models differed in the substitutions of variables that were highly correlated, i.e. we did not allow highly correlated variables to feature in the same global model (those with Spearman's rank coefficients $>0.6$, Appendix S4). Also substituted were landscape metrics if they were non-independent and quantified the same driver (forest cover or landscape diversity) but at different extents (buffer sizes). From these global models, we generated a full set of nested models, all to be compared with Akaike's Information Criterion (AIC) using R (v. 3.4.3; R Core Team 2014) with the dredge function from package MuMIn (Bartoń 2016; see Appendix S4). We identified a single, minimum adequate model as the model with the lowest AIC value (Burnham and Anderson 2002). By constructing and comparing models with a specific interaction among variables (e.g. temperature * landscape diversity), that corresponded to an a priori hypothesis, we distinguish our testing of rigorous hypotheses from a 'fishing expedition' that seeks significant predictors among a large group of contenders and all of their possible second or third order interactions (Burnham and Anderson 2002). We used model selection to obtain model coefficients, rather than averaging models over multiple models with similar support (Spake et al. 2019a). This is because models differing only in the extent of landscape variables are likely to have very similar support, and such models cannot be averaged as they are technically different variables measuring the same quantity (Freckleton 2011).

The area over which landscape variables influence an ecological phenomenon at a focal point, the 'ecological neighbourhood' (Addicott et al. 1987) or 'scale of effect' (Holland et al. 2004), is typically identified by comparing models with landscape variables quantified at varying extents (buffer sizes) surrounding a focal point and selecting the extent yielding the best fit. The scale of effect of the landscape-level driver (landscape diversity or forest cover) was identified as the scale that featured in the minimum adequate model for the response variable in question. We favour this approach over the often-used practice of fitting multiple univariate models for each extent of each landscape variable (e.g. Holland et al. 2004; Soranno et al. 2015), because univariate models necessarily omit important variables and interactions, increasing residual variance and leading to a bias in the statistical inference (Bradter et al. 2013).

To ascertain relative variable importance, we re-ran model selection with landscape metric at the scale selected by the minimum adequate model. AIC was used to select a set of substantially supported models $(\triangle \mathrm{AIC} \leq 2$ according to Burnham and Anderson 2002; Aho et al. 2014). Importance values were then calculated by summing the Akaike weights of models that included the term in question (Burnham and Anderson 2002).

We ensured that generalised linear models satisfied model assumptions by inspecting standardised residuals using the DHARMa package (Hartig 2018). The goodness of fit of each model was calculated following Nagelkerke (1991) for models of richness and abundance. Explanatory variables were centred and scaled prior to analysis to improve interpretability of regression coefficients (Schielzeth 2010). Variance inflation factors were calculated to ensure models were not subject to multicollinearity using a threshold of 2 for mean-centred and scaled variables (Zuur et al. 2010). We used R packages visreg (Breheny and Burchett 2017) and ggplot2 (Wickham 2016) to visualise the regression outputs.

\section{Results}

\section{Taxonomic diversity}

A total of 23,077 individuals of 68 species (listed in Appendix S5) were sampled between 2009 and 2015 across the 297 study sites in total, with site-level maximum abundance and richness ranging between 9 and $260($ mean $=77.7 ; \mathrm{SD}=37.4)$, and 6 to 34 
$($ mean $=17.0 ;$ SD $=4.9)$, respectively. Species richness and Shannon diversity were highly correlated (Spearman's rho $=0.93$, Appendix S3), so only analyses of richness and abundance are presented. Minimum adequate models explained little variation in richness and abundance (pseudo- $R^{2}$ values of 0.11 and 0.08 , respectively). Richness and abundance exhibited weak responses to mean annual temperature: richness a hump-shaped relationship and abundance exhibited a linear increase (Appendix S5). Both richness and abundance declined with increasing annual rainfall. Landscape heterogeneity variables (landscape diversity or forest cover) did not feature in the minimum adequate model, and was relatively unimportant across substantially supported models (importance values $<0.2$; Appendix S5).

\section{Community-level trait means and trait diversity}

Contrary to the taxonomic metrics describing bird communities, functional traits were considerably explained by the environmental predictors considered in our study ( $R^{2}$ values ranged between 0.27 and 0.58 ). Trait means and diversities exhibited contrasting responses to environmental drivers. Landscape diversity, rather than proportional forest amount, consistently explained greater variation in functional responses across all trait measures (mean and diversity). Here we present the results of minimum adequate models; see Supplementary information for full results.

\section{Habitat breadth}

The mean and diversity of habitat breadth exhibited contrasting, temperature-dependent, responses to landscape diversity. The minimum adequate models, explaining $58 \%$ and $34 \%$ of variation in the mean and diversity of habitat breadth, respectively, included landscape diversity characterised within $500-\mathrm{m}$ of a forest site, mean annual temperature and their interaction, in addition to annual rainfall (Appendix S6). Overall, temperature exerted positive effects on mean habitat breadth; cooler regions consisted of communities dominated by species sharing similar, narrow habitat breadths. Mean habitat breadth increased linearly with landscape diversity, with the magnitude of the effect dependent on temperature; a stronger landscape diversity effect was observed in cool regions, and weaker effect in warmer regions (Fig. 2a). The effect of landscape diversity on habitat breadth diversity, on the other hand, changed in both magnitude and direction across the temperature gradient (Fig. 2b). Increasing landscape diversity was consistent with divergence of this trait in cooler regions, while increasing convergence was observed in warmer regions. These results suggest that in cool regions, homogeneous, contiguous landscapes support specialists only (species with narrow habitat breadths), while generalist species (with wider habitat breadths) inhabit homogeneous landscapes in warmer regions. Diverse landscapes in cooler regions tend to support both specialist and generalist species, while in warm regions, increasingly transformed landscapes support generalist species with increasingly similar and widening habitat breadths.

\section{Diet}

Mean insectivory (the proportion of diet consisting of insects) declined strongly with increasing temperature, while diet diversity increased (Fig. 3; Appendix S7). The effect of landscape diversity (within a 1-km buffer) on mean insectivory was weakly negative overall, while its effect on diet diversity changed in strength and magnitude across the temperature gradient, with positive effects in cool regions, and negative effects in warm regions (Fig. 3). This suggests that in cooler regions, particularly in highly forested, homogeneous landscapes, insectivores dominate bird communities, while in warmer regions communities are dominated by a variety of dietary guilds (i.e. insectivores, granivores and frugivores), particularly in homogeneous landscapes. The minimum adequate models explained $47 \%$ and $25 \%$ variation in the mean and diversity of the diet trait, respectively.

\section{Discussion}

Our study provides evidence that regional variation in species pools, a consequence of past historical disturbance, broad-scale climate and resource quality (Appendix S1), leads to differential functional responses of avian communities to landscape heterogeneity across Japan. Our findings therefore reveal contextdependent functional responses to environmental drivers, which must be understood for effective 


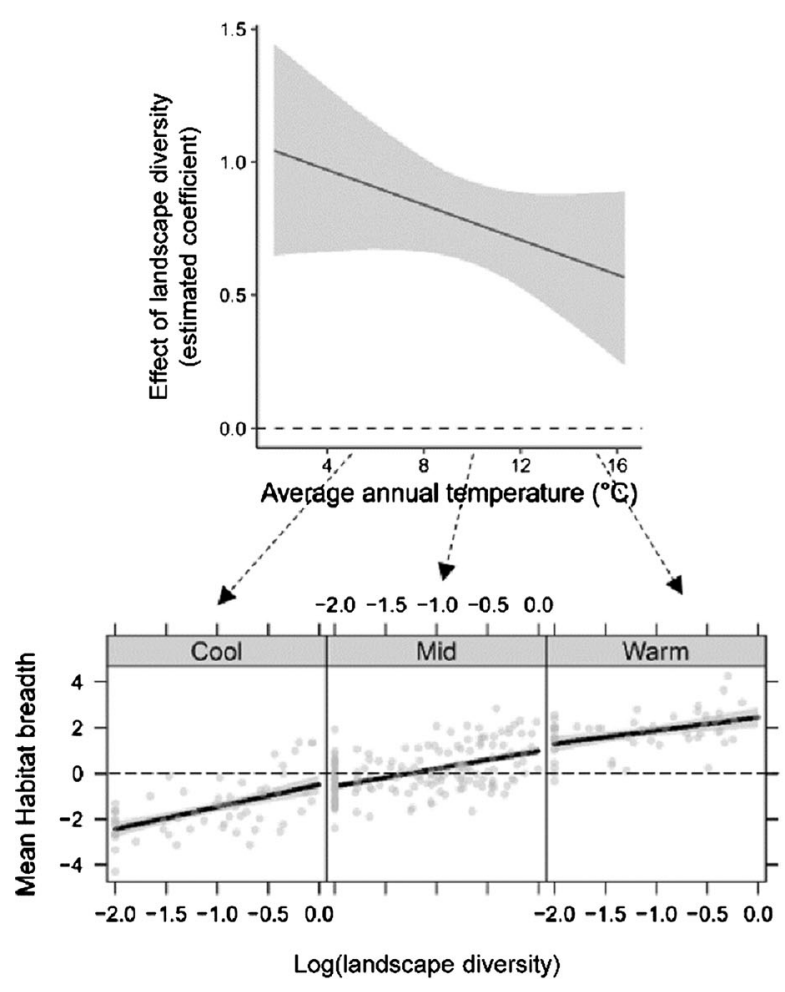

Fig. 2 Impacts of landscape diversity on mean habitat breadth (left) diversity (right) of forest bird communties as dependent on annual mean temperature. Top: Johnson-Neyman confidence bands surrounding the marginal effects of landscape diversity, conditional on average annual temperature. Dashed arrows at 5 , 10 and $15^{\circ} \mathrm{C}$ show effects corresponding to panels below. Middle: Influence of landscape diversity on habitat breadth mean and diversitiy at mean annual temperatures of 5, 10 and

implementation of landscape-scale conservation initiatives (Spake et al. 2019a). Landscape diversity, rather than proportional forest amount, consistently explained greater variation in functional responses across all trait measures (mean and diversity). As these variables were highly correlated (Spearman's rho = 0.99; Appendix S2), we discuss our results in terms of community responses to 'landscape heterogeneity'.

The effects of landscape heterogeneity on mean habitat breadth and habitat breadth diversity varied with the temperature gradient, as predicted. In cool regions of Japan, highly forested, homogeneous landscapes supported bird communities dominated by forest specialists: those with narrow habitat breadths and highly insectivorous diets. The abundance of species with generally wider and slightly variable habitat breadths increased with landscape heterogeneity. This finding agrees with conceptual and

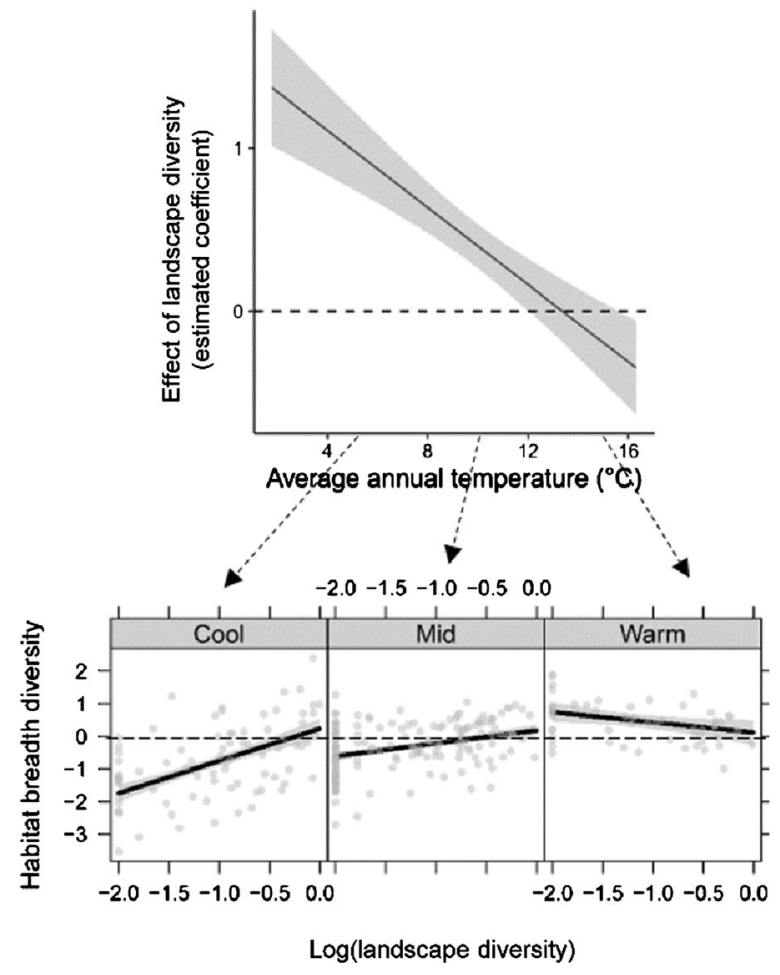

$15{ }^{\circ} \mathrm{C}$, showing grey-shaded $95 \% \mathrm{CI}$ in the regression and partial residual points. Shown are standardised effect sizes; values above 0 (dashed lines) signify trait divergence, while values below 0 signify trait convergence. Landscape diversity represents the $\log _{10}$ of shannon diversity of proportional land covers measured in a buffer of radius $500-\mathrm{m}$. Plots used coefficients of the minimum adequate models. Response variables were standardised effect sizes, see text

empirical work showing that heterogeneous landscapes can provide more niches or complementary/supplementary resources for a wider range of species' traits (Tscharntke et al. 2012; Duflot et al. 2014), provided that a diversity of traits are present in the species pool. Warmer regions comprised communities dominated by species with wider habitat breadths, even in relatively homogeneous, highly forested landscapes, reflecting a loss of specialists from the species pool. Habitat breadth diversity declined with landscape heterogeneity, towards convergent communities of species with only wide breadths, suggesting that forest specialists with narrow breadths were unable to persist within heterogeneous landscapes. This is consistent with our hypothesis (Fig. 1). In other words, landscape heterogeneity can only promote functional trait diversity in regions where both specialists and generalists are supported by 

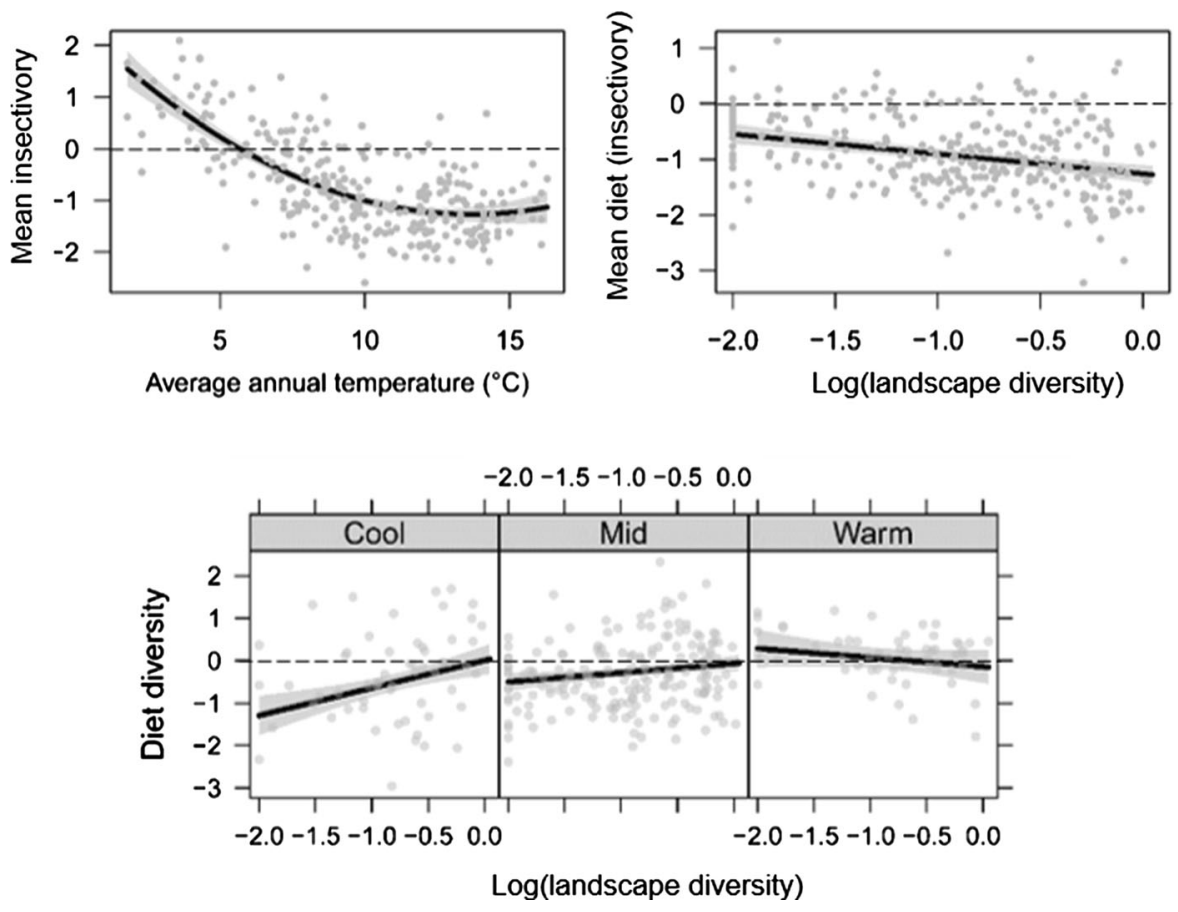

Fig. 3 Response of mean insectivory (top) and diet diversity (bottom) to temperature and landscape diversity showing greyshaded $95 \% \mathrm{CI}$ in the regression and partial residual points. Diet diversity responses to landscape diversity are shown at mean annual temperatures of $-1,5$ and $11{ }^{\circ} \mathrm{C}$. Shown are standardised effect sizes; values above 0 (dashed lines) signify trait

high habitat quality. A somewhat surprising, yet important, finding is the strength of the relationships we detected (as measured by explained variation), given the relatively narrow range in forest cover studied (between 60 and $100 \%$ within $2-\mathrm{km}$ of survey sites).

Our result of regional-dependent responses to landscape heterogeneity concurs with a global metaanalysis demonstrating weaker patch size-density relationships in eastern than western continents, which are dominated by area-insensitive generalists (Bender et al. 1998). Our findings also agree with observations that while the species richness and abundance of forest birds are strongly positively related to forest area in both eastern North America and Japan, these relationships are weaker in western North America and Europe, which have experienced more extensive forest clearing over a longer time period (George and Dobkin 2002; Kurosawa and Askins 2003). Similarly, in a global analysis of fragmentation effects on 4489 animal species, Betts et al. (2019) found that that the means that are greater than expected at random, or trait divergence, while values below 0 signify trait means that are lower than expected at random, or trait convergence. Landscape diversity represents the $\log _{10}$ of shannon diversity of proportional land covers measured in a buffer of radius $1-\mathrm{km}$. Plots used coefficients of the minimum adequate models

proportion of fragmentation-sensitive species was nearly three times higher in regions with low historical disturbance rates than with regions with high rates of e.g. fires, glaciation, hurricanes, and deforestation.

The effects of landscape heterogeneity on dietary diversity also varied with the temperature gradient, with mean insectivory declining with increasing temperature and landscape heterogeneity. Our finding of a higher prevalence of insectivorous diets in less transformed landscapes with intact forest agrees with previous demonstrations of lower insectivore richness and abundance in disturbed than undisturbed forest (Gray et al. 2007), and landscapes with decreasing forest cover (Lindenmayer et al. 2015) and patch area (Watson et al. 2005).We therefore add support to the finding that insectivorous birds are less resilient to high-intensity than low-intensity land use (Karp et al. 2011). As expected, a main effect of temperature on insectivory was detected, as in Japan, forests in cool regions tend to comprise broadleaved deciduous tree species that support great densities of caterpillars, and 
therefore insectivores, during the growing season (Blondel et al. 1993; Huston and Wolverton 2008). Contrary to expectation however, we found dietary diversity to increase only weakly, towards random expectation, in cool regions. This might be because there are abundant immigrant birds even in transformed landscapes, since cooler regions support abundant food resources. The presence of immigrant birds could therefore blur or reduce any effects of landscape heterogeneity on community-level insectivory or diversity in cool regions (Bollinger and Switzer 2002).

Our study showed that species richness was explained poorly by landscape heterogeneity, contrasting with similar studies measuring biodiversity responses within focal habitats in Japan (Natuhara and Imai 1999). Functional rather than taxonomic descriptors of bird communities were better explained by environmental variation, likely because the scale at which species interact with, and respond to landscapes, depends on their functional traits (Suárezcastro et al. 2018). Indeed, previous studies that report strong responses of species richness in Japan have typically analysed richness within different a priori functional groupings, e.g. by habitat specialism, range size (Katayama et al. 2014), or guild (Yoshikawa et al. 2017), consistent with the functional responses we detected. Total species richness markedly declines with temperature at macro-scales in Japan (Yamaura et al. 2011), reflecting a decline in the regional species pool. Despite this regional decline in richness, similar numbers of species are supported locally, but comprise communities differing in functional composition in forested landscapes, dealt with in this study.

\section{Caveats}

We identified a statistical interaction between temperature and landscape heterogeneity gradients in explaining bird functional responses. However, temperature, historical disturbance and the predominance of deciduous over evergreen forests (and therefore the quality of forest as a food resource during the breeding season) were inextricably confounded in our study area (Appendix S1), so we could not investigate the independent effects of temperature. Independently, temperature could have conceivably exerted opposite effects on functional trait means and diversity as historical disturbance, weakening the overall additive and interactive effect of historical disturbance intensity observed in this study. Understanding community responses to temperature independently will become more important under global change, where temperature could decouple with the gradients that it currently correlates with, yielding novel climates.

We observed weaker effects than hypothesised (Fig.1). There are several possible reasons for this. Firstly, an apparent sampling bias towards forest sites in more heavily forested landscapes, in addition to our subsampling of data to reduce outliers (see methods), means that we present trends over a restricted gradient of forest cover (60-100\%; Appendix S2). A wider gradient encompassing lower forest cover and greater diversity may have led to greater deviation from null communities (Brennan et al. 2002; Eigenbrod et al. 2011). Secondly, we present analyses of communities surveyed from forest sites only due to data limitations. A stronger trend would likely have been observed if communities were sampled across all constituent habitat types (i.e. gamma diversity). Sampling other habitat types may have sampled non-forest specialists, such as grassland specialists, leading to a higher degree of trait divergence, and more so in less disturbed, cooler regions of Japan that can sustain such specialists. Finally, a lack of deviation from null communities in heterogeneous landscapes may signify the simultaneous effect of multiple, opposing processes (Botta-Dukát and Czúcz 2016): habitat filtering, which leads to lower variation in trait values than random selection from the species pool (convergence), and limiting similarity, wherein co-existence relies on species exploiting different niches (divergence). Our inability to detect and formalise all processes at play is an enduring issue in ecology; with more potential processes that structure species assemblages than there are resulting patterns (Lessard et al. 2016). It would be interesting to further survey less forested, highly heterogeneous landscapes, whereby temperature and historical disturbance are easier to disentangle.

A key challenge to the study of biodiversity responses to landscape pattern using observational datasets is multicollinearity among landscape metrics such as proportional cover and landscape diversity (Fahrig et al. 2011). This is a particular issue when conducting analyses across broad geographic extents, where the landscape attributes that drive measured diversity may vary regionally. Characterisation of the data structure (Appendix S2) shows that land cover 
responsible for driving landscape diversity may exhibit slight regional dependence. In warmer regions, landscape heterogeneity was driven more by cropland and wetland habitats, and by grasslands in cooler regions. Specialists were still able to persist in transformed landscapes in cooler regions, which may have been partly due to a less hostile matrix in cooler than warmer regions. Future survey efforts should aim to disentangle these effects and sample full gradients of landscape composition within different biomes in Japan.

Imperfect detection of species may bias measures of functional trait composition and diversity, leading to incorrect estimates of trait-environment relationships due to a process of 'detection filtering', where ecologically important traits, such as body mass, influence the probability of species detection during field surveys (Roth et al. 2018). However, measures are likely to be robust to detection filtering if the effects of the environment on functional composition and diversity are larger than the effects of detection (Roth et al. 2018) or they are not confounded with each other (Banks-Leite et al. 2014). We did not consider this to be an issue in our study, because we used a maximum of a 50-m detection radius, within which the detection probability of songbirds has been shown to be high across a range of habitats, and therefore likely also gradients of landscape heterogeneity (Schieck 1997; Alldredge et al. 2007; Yamaura and Royle 2017). The likelihood of detection filtering was further reduced by our use of the maximum abundance values (see methods), assuming that the maximum number of birds detected in any visit represents the minimum number at that location (Bibby et al. 2000). In addition, modelled maximum point-counts have been shown to produce better model fits with territory abundance than mean point-counts (Toms et al. 2006). Moreover, as we only included forest surveys in our analysis (we excluded surveys conducted in grasslands), detection probability is unlikely to have varied systematically with habitat type. Finally, the effects of potential covariates on detection probability were minimised because the bird surveys were only conducted on days without rain or strong winds to minimise variation in detection probability, reducing the likelihood that detection would vary with climatic gradients (Banks-Leite et al. 2014).

\section{Implications for future research and management}

Much research in landscape ecology seeks to identify whether certain landscape properties, such as landscape heterogeneity, have universal effects (e.g. Stein et al. 2014). Our study shows that regional variation in climate and disturbance histories, and consequently species pools, can generate vast differences in landscape effects on biotic communities. We therefore suggest that future research should consider interactions between landscape- and local-level environmental drivers and regional context, as any contingencies will have important management implications. Landscape management designs developed for one regional context may not be effectively transferred to others that differ in climate, habitat quality, or history. Moreover, funds for biodiversity conservation are scarce, so we must effectively and efficiently allocate resources to prevent long-term loss and degradation of natural systems. Our approach could act as a useful framework for investigating the context dependence of landscape effects, allowing us to develop tailored management plans accounting for regional context.

Data accessibility statement

Bird community data are available from the Ministry of the Environment (https://www.biodic.go.jp/ moni1000/findings/data/index_file_terrestrialbird.

html [in Japanese]), while climate data are available from the Meteorological Agency of Japan (https:// nlftp.mlit.go.jp/ksj/index.html [in Japanese]). Bird diet data are available on figshare: https://figshare. com/articles/Data_Paper_Data_Paper/3559887, while other traits can be accessed using JAVIAN (Takagawa et al. 2011) and in Cooke et al. (2019).

Acknowledgements This research was funded by a Japan Society for the Promotion of Science Bridge Fellowship awarded to RS, and an ERC Starting Grant "SCALEFORES" [Grant No. 680176] awarded to FE. We thank the surveyors who contributed data to this project. We thank three anonymous reviewers for their suggested improvements to earlier versions of this manuscript.

Open Access This article is licensed under a Creative Commons Attribution 4.0 International License, which permits use, sharing, adaptation, distribution and reproduction in any medium or format, as long as you give appropriate credit to the original author(s) and the source, provide a link to the Creative Commons licence, and indicate if changes were made. The images or other third party material in this article are included in 
the article's Creative Commons licence, unless indicated otherwise in a credit line to the material. If material is not included in the article's Creative Commons licence and your intended use is not permitted by statutory regulation or exceeds the permitted use, you will need to obtain permission directly from the copyright holder. To view a copy of this licence, visit http://creativecommons.org/licenses/by/4.0/.

\section{References}

Addicott J, Aho J, Antolin M, Padilla D, Richardson J, Soluk D (1987) Ecological neighborhoods: scaling environmental patterns. Oikos 49:340-346

Aho K, Derryberry D, Peterson T (2014) Model selection for ecologists: the worldviews of AIC and BIC. Ecology 95(3):631-636. https://doi.org/10.1890/13-1452.1

Alldredge MA, Simons TR, Pollock KH (2007) Factors affecting aural detections of songbirds. Ecol Appl 17:948-955

Askins RA (1992) Forest fragmentation and the decline of migratory songbirds. Bird Obs 20:13-21

Banks-Leite C, Pardini R, Boscolo D, Cassano CR, Püttker T, Barros CS, Barlow J (2014) Assessing the utility of statistical adjustments for imperfect detection in tropical conservation science. J Appl Ecol 51:849-859

Bartoń K (2016) MuMIn: Multi-model inference. R package version 1.15.6

Bello FD, Leps J, Pakeman RJ, Kleyer M, Thuiller W, Lavorel S (2012) Assessing species and community functional responses to environmental gradients: which multivariate methods? J Veg Sci 23:805-821

Bender DJ, Contreras TA, Fahrig L (1998) Habitat loss and population decline: a meta-analysis of the patch size effect. Ecology 79:517-533

Betts MG, Wolf C, Pfeifer M, Banks-Leite C, Arroyo-Rodríguez V, Ribeiro DB, Barlow J, Eigenbrod F, Faria D, Hadley AS, Hawes JE, Holt RD, Kormann BKU, Lens L, Levi T, Medina-Rangel GFLS, Mezger MDC, Orme DL, Peres CA, Phalan BT, Pidgeon A, Possingham H, Ripple WJ, Slade EM, Somarriba E, Tobias JA, Tylianakis JM, UrbinaCardona JN, Valente JJ, Watling JI, Wells K, Wearn OR, Wood E, Young R, Ewers RM (2019) Extinction filters mediate the global effects of habitat fragmentation on animals. Science 1239:1236-1239

Bibby C, Burgess N, Hill D, Mustoe S (2000) Bird census techniques, 2nd edn. Academic Press, London

Blake JG (1983) Trophic structure of bird communities in forest patches in east-central Illinois. Wilson Bull 95:416-430

Blondel J, Dias PC, Maistre M, Perret P (1993) Habitat heterogeneity and life-history variation of Mediterranean Blue Tits (Parus caerulius). Auk 110:511-520

Blonder B, Lamanna C, Violle C, Enquist BJ (2014) The n-dimensional hypervolume. Glob Ecol Biogeogr 23:595-609

Bollinger EK, Switzer P (2002) Modeling the impact of edge avoidance on avian nest densities in habitat fragments. Ecol Appl 12:1567-1575

Botta-Dukát Z, Czúcz B (2016) Testing the ability of functional diversity indices to detect trait convergence and divergence using individual-based simulation. Methods Ecol Evol $7: 114-126$

Bradter U, Kunin WE, Altringham JD, Thom TJ, Benton TG (2013) Identifying appropriate spatial scales of predictors in species distribution models with the random forest algorithm. Methods Ecol Evol 4:167-174

Breheny P, Burchett W (2017) Visualization of Regression Models Using visreg. R J 9:56-71

Brennan JM, Bender DJ, Contreras TA, Fahrig L (2002) Focal patch landscape studies for wildlife management: optimizing sampling effort across scales. In: Liu J, Taylor WW (eds) Integrating Landscape Ecology into Natural Resource Management. Cambridge University Press, Cambridge, pp 68-91

Burnham KP, Anderson DR (2002) Model selection and multimodel inference: a practical information-theoretic approach, 2nd edn. Springer-Verlag, New York

Chalfoun AD, Thompson FR, Ratnaswamy MJ (2002) Nest predators and fragmentation: a review and meta-analysis. Conserv Biol 16:306-318

Clavel J, Julliard R, Devictor V (2011) Worldwide decline of specialist species: Toward a global functional homogenization? Front Ecol Environ 9:222-228

Concepción ED, Götzenberger L, Nobis MP, de Bello F, Obrist MK, Moretti M (2017) Contrasting trait assembly patterns in plant and bird communities along environmental and human-induced land-use gradients. Ecography 40:753-763

Connor EF, Courtney AC, Yoder JM (2000) Individuals-area relationships: the relationship between animal population density and area. Ecology 81:734-748

Conradi T, Kollmann J (2016) Species pools and environmental sorting control different aspects of plant diversity and functional trait composition in recovering grasslands. J Ecol 104:1314-1325

Cooke RSC, Bates AE, Eigenbrod F (2019) Global trade-offs of functional redundancy and functional dispersion for birds and mammals. Glob Ecol Biogeogr 00:1-12

Coster GD, Banks-leite C, Metzger JP (2015) Atlantic forest bird communities provide different but not fewer functions after habitat loss. Proc R Soc B 282:20142844

Duflot R, Georges R, Georges R, Ernoult A, Aviron S, Burel F (2014) Landscape heterogeneity as an ecological filter of species traits. Acta Oecol 56:19-26

Eigenbrod F, Hecnar SJ, Fahrig L (2011) Sub-optimal study design has major impacts on landscape-scale inference. Biol Conserv 144:298-305

Ellis EC (2011) Anthropogenic transformation of the terrestrial biosphere. Philos Trans R Soc B 369:1010-1035

Ellis EC, Ramankutty N (2008) Putting people in the map: anthropogenic biomes of the world. Front Ecol Environ 6:439-447

Fahrig L, Baudry J, Brotons L, Burel FG, Crist TO, Fuller RJ, Sirami C, Siriwardena GM, Martin JL (2011) Functional landscape heterogeneity and animal biodiversity in agricultural landscapes. Ecol Lett 14:101-112

Fletcher RJ (2005) Multiple edge effects and their implications in fragmented. J Anim Ecol 74:342-352

Freckleton RP (2011) Dealing with collinearity in behavioural and ecological data: Model averaging and the problems of measurement error. Behav Ecol Sociobiol 65:91-101 
Fujita G, Azuma A, Nonaka J, Sakai Y, Sakai H (2016) Context dependent effect of landscape on the occurrence of an apex predator across different climate regions. PLoS ONE 11:e0153722

Fukasawa K, Akasaka T (2019) Long-lasting effects of historical land use on the current distribution of mammals revealed by ecological and archaeological patterns. Sci Rep 9:1-11

Garnier E, Cortez J, Billès G, Navas M, Roumet C, Debussche M, Laurent G, Blanchard A, Aubry D, Bellmann A, Neill C, Toussaint JP (2004) Plant functional markers capture ecosystem properties during secondary succession. Ecology 85:2630-2637

George TL, Dobkin DS (2002) Introduction: habitat fragmentation and western birds. In: George TL, Dobkin DS (eds) Effects of habitat fragmentation on birds in western landscapes: contrasts with paradigms from the eastern United States. Studies in avian biology no. 25. Cooper Ornithological Society, Kansas

Gerstner K, Moreno-mateos D, Gurevitch J, Beckmann M, Kambach S, Jones HP, Seppelt R (2017) Will your paper be used in a meta-analysis? Make the reach of your research broader and longer lasting. Methods Ecol Evol 8:777-784

Gilroy JJ, Uribe CAM, Haugaasen T, Edwards DP (2014) Effect of scale on trait predictors of species responses to agriculture. Conserv Biol 29:463-472

Gotelli NJ, McCabe DJ (2002) Species co-occurrence: a metaanalysis of J.M. Diamond's assembly rules model. Ecology 83:2091-2096

Gray MA, Baldauf SL, Mayhew PJ, Hill JK (2007) The response of avian feeding guilds to tropical forest disturbance. Conserv Biol 21:133-141

Grueber CE, Nakagawa S, Laws RJ, Jamieson IG (2011) Multimodel inference in ecology and evolution: challenges and solutions. J Evol Biol 24:699-711

Harrison XA (2015) A comparison of observation-level random effect and Beta-Binomial models for modelling overdispersion in Binomial data in ecology \& evolution. PeerJ 3:e1114

Hartig F (2018) DHARMa: residual diagnostics for hierarchical (multi-level/mixed) regression models. R package version 0.2 .0

Holland JD, Bert DG, Fahrig L (2004) Determining the spatial scale of species' response to habitat. Bioscience 54:227

Holmes RT, Sherry TW, Sturges FW, Trends FL, Hubbard AT, Holmes RT, Sherry TW, Sturges FW (1986) Bird community dynamics in a temperate deciduous forest: longterm trends at Hubbard Brook. Ecol Monogr 56:201-220

Huston MA, Wolverton S (2008) The global distribution of net primary production: resolving the paradox. Ecol Monogr 79:343-377

Huston MA, Wolverton S (2009) The global distribution of net primary production: resolving the paradox. Ecol Monogr 79:343-377

Jin Y, Didham RK, Yuan J, Hu G, Yu J, Zheng S, Yu M (2019) Cross-scale drivers of plant trait distributions in a fragmented forest landscape. Ecography 42:1-13

Karp DS, Ziv G, Zook J, Ehrlich PR, Daily GC (2011) Resilience and stability in bird guilds across tropical countryside. Proc Natl Acad Sci 108:21134-21139
Katayama N, Amano T, Naoe S, Yamakita T, Komatsu I, Takagawa SI, Sato N, Ueta M, Miyashita T (2014) Landscape heterogeneity-biodiversity relationship: effect of range size. PLoS ONE 9:1-8

Kawamura K, Yamaura Y, Senzaki M, Ueta M, Nakamura F (2019) Seasonality in spatial distribution: climate and land use have contrasting effects on the species richness of breeding and wintering birds. Ecol Evol 9:7549-7561

Kembel SW, Cowan PD, Helmus MR, Cornwell WK, Morlon H, Ackerly DD, Blomberg SP, Webb CO (2010) Picante: R tools for integrating phylogenies and ecology. Bioinformatics 26:1463-1464

Klingbeil BT, Willig MR (2016) filtering, interspecific interactions and priority effects. Evol Ecol 30:703-722

Kurosawa R, Askins RA (2003) Effects of habitat fragmentation on birds in deciduous forests in Japan. Conserv Biol 17:695-707

Laliberte E, Legendre P (2010) A distance-based framework for measuring functional diversity from multiple traits. Ecology 91:299-305

Laliberté E, Wells JA, Declerck F, Metcalfe DJ, Catterall CP, Queiroz C, Aubin I, Bonser SP, Ding Y, Fraterrigo JM, McNamara S, Morgan JW, Merlos DS, Vesk PA, Mayfield MM (2010) Land-use intensification reduces functional redundancy and response diversity in plant communities. Ecol Lett 13:76-86

Laliberté E, Legendre P, Shipley B (2014) FD: measuring functional diversity from multiple traits, and other tools for functional ecology. R package version 1.0-12.

Lessard J, Belmaker J, Myers JA, Chase JM, Rahbek C (2012a) Inferring local ecological processes amid species pool influences. Trends Ecol Evol 27:600-607

Lessard J, Weinstein BG, Borregaard MK, Marske KA, Martin DR, Mcguire JA, Parra JL, Rahbek C, Graham CH (2016) Process-based species pools reveal the hidden signature of biotic interactions amid the influence of temperature filtering. Am Nat 187:75-88

Lindenmayer D, Blanchard W, Tennant P, Barton P, Ikin K, Mortelliti A, Okada S, Crane M, Michael D (2015) Richness is not all: how changes in avian functional diversity reflect major landscape modification caused by pine plantations. Divers Distrib 21:836-847

Luck GW, Carter A, Smallbone L (2013) Changes in bird functional diversity across multiple land uses: interpretations of functional redundancy depend on functional group identity. PLoS ONE 8:e63671

Matsuoka SM, Mahon CL, Handel CM, Bayne EM, Patricia C, Ralph CJ (2014) Reviving common standards in pointcount surveys for broad inference across studies. Condor 116:599-608

Mayfield M, Bonder S, Morgan J, Aubin I, McNamara S, Vesk PA (2010) ECOLOGICAL what does species richness tell us about functional trait diversity? Predictions and evidence for responses of species and functional trait diversity to land-use change. Glob Ecol Biogeogr 19:423-431

McGill BJ, Enquist BJ, Weiher E, Westoby M (2006) Rebuilding community ecology from functional traits. Trends Ecol Evol 21:178-185

Miller JR, Dixon MD, Turner MG (2004) Response of avian communities in large-river floodplains to environmental variation at multiple scales. Ecol Appl 14:1394-1410 
Ministry of the Environment (2018) Biodiversity center of Japan. Ministry of the Environment, Chiyoda

Morissette JL, Bayne EM, Kardynal KJ, Hobson KA (2019) Regional variation in responses of wetland-associated bird communities to conversion of boreal forest to agriculture. Avian Conserv Ecol 14:12

Nagelkerke N (1991) A note on a general definition of the coefficient of determination. Biometrika 78:691-692

Natuhara Y, Imai C (1999) Prediction of species richness of breeding birds by landscape-level factors of urban woods in Osaka Prefecture, Japan. Biodivers Conserv 8:239-253

Newbold T, Hudson L, Hill SLL, Contu S, Senior RA, Borger L, Lysenko I, Bennett DJ, Choimes A, Collen B, Day J, Palma AD, D1 S, Edgar MJ, Feldman A, Garon M, Harrison MLK, Alhusseini T, Echeverria-london S, Ingram DJ, Itescu Y, Kattge J, Kemp V, Kirkpatrick L, Kleyer M, Laginha D, Correia P, Martin CD, Meiri S, Novosolov M, Pan Y, Phillips HRP, Purves DW, Robinson A, Simpson J, Tuck SL, Weiher E, White HJ, Ewers RM, Mace GM, Scharlemann JPW, Purvis A (2015) Global effects of land use on local terrestrial biodiversity. Nature 2:45

Pasher J, Mitchell SW, King DJ, Fahrig L, Smith AC, Lindsay KE (2013) Optimizing landscape selection for estimating relative effects of landscape variables on ecological responses. Landsc Ecol 28:371-383

Peters DPC, Bestelmeyer BT, Turner MG (2007) Cross-scale interactions and changing pattern-process relationships: consequences for system dynamics. Ecosystems 10:790-796

R Core Team (2014) R: a language and environment for statistical computing. R Foundation for Statistical Computing, Vienna, Austria. http://www.R-project.org/

Ralph CJ, Martin TE, Geupel GR, Desante DF, John C, Geoffrey R, Thomas E, Handbook DF (1993) Handbook of field methods for monitoring landbirds. USDA Forest Service general technical report PSW-GTR-144. USDA Forest Service, Washington, DC

Randin CF, Dirnbock T, Dullinger S, Niklaus E, Randin CF, Dirnbo T, Zappa M, Guisan A (2006) Are niche-based species distribution models transferable in space? J Biogeogr 33:1689-1703

Rao CR (1982) Diversity and dissimilarity coefficients-a unified approach. Theor Popul Biol 21:24-43

Rhodes JR, Callaghan JG, Mcalpine CA, Jong CD, Bowen ME, Mitchell DL, Lunney D, Possingham HP (2008) Regional variation in habitat-occupancy thresholds: a warning for conservation planning. J Appl Ecol Ecol 45:549-557

Ribera I, Dolédec S, Downie IS, Foster GN (2001) Effect of land disturbance and stress on species traits of ground beetle assemblages. Ecology 82:1112-1129

Ries L, Fletcher RJ, Battin J, Sisk TD (2004) Ecological responses to habitat edges: Mechanisms, models, and variability explained. Annu Rev Ecol Syst 35:491-522

Roth T, Allan E, Pearman PB, Amrhein V, Roth T (2018) Functional ecology and imperfect detection of species. Methods Ecol Evol 9:917-928

Saito MU, Momose H, Inoue S, Kurashima O (2016) Rangeexpanding wildlife : modelling the distribution of large mammals in Japan, with management implications. Int $\mathbf{J}$ Geogr Inf Sci 30:20-35
Schieck JIM (1997) Biased detection of bird vocalizations affects comparisons of bird abundance among forested habitats. Condor 99:179-190

Schielzeth H (2010) Simple means to improve the interpretability of regression coefficients: interpretation of regression coefficients. Meth Ecol Evol 1(2):103-113. https://doi.org/10.1111/j.2041-210X.2010.00012.x

Shackelford N, Starzomski BM, Banning NC, Battaglia LL, Becker A, Bellingham PJ, Bestelmeyer B, Catford JA, Dwyer JM, Dynesius M, Gilmour J, Hallett LM, Hobbs RJ, Price J, Sasaki T, Tanner EVJ, Standish RJ (2016) Isolation predicts compositional change after discrete disturbances in a global meta-study. Ecography 40:1256-1266

Shipley B (2007) Comparative plant ecology as a tool for integrating across scales. Ann Bot 99:965-966

Soranno PA, Cheruvelil KS, Wagner T, Webster KE, Bremigan MT (2015) Effects of land use on lake nutrients: the importance of scale, hydrologic connectivity, and region. PLOS ONE 10:1-22

Spake R, Barsoum N, Newton AC, Doncaster CP (2016) Drivers of the composition and diversity of carabid functional traits in UK coniferous plantations. For Ecol Manag 359:300-308

Spake R, Bellamy C, Graham L, Watts K, Wilson T, Norton L, Wood C, Schmucki R, Bullock J, Eigenbrod F (2019a) An analytical framework for spatially targeted management of natural capital. Nat Sustain 2(2):90-97

Spake R, Doncaster CP (2017) Use of meta-analysis in forest biodiversity research: key challenges and considerations. For Ecol Manag 400:429-437

Spake R, Yanou S, Yamaura Y, Kawamura K, Kitayama K, Doncaster CP (2019b) Meta-analysis of management effects on biodiversity in plantation and secondary forests of Japan. Conserv Sci Pract 1:14

Stein A, Gerstner K, Kreft H (2014) Environmental heterogeneity as a universal driver of species richness across taxa, biomes and spatial scales. Ecol Lett 17:866-880

Suzuki SN, Ishihara MI, Hidaka A (2015) Regional-scale directional changes in abundance of tree species along a temperature gradient in Japan. Glob Change Biol 21:3436-3444

Suárez-castro AF, Simmonds JS, Mitchell MGE, Maron M, Rhodes JR (2018) The scale-dependent role of biological traits in landscape ecology: a review. Curr Landsc Ecol Rep 3:12-22

Takagawa S, Ueta M, Amano T, Okahisa Y, Kamioka M (2011) JAVIAN Database: a species-level database of life history, ecology and morphology of bird species in Japan. Bird Res 7:R9-R12 (In Japanese)

Takeuchi K (2010) Rebuilding the relationship between people and nature: the Satoyama Initiative. Ecol Res 25:891-897

Toms JD, Schmiegelow FKA, Hannon SJ, Villard M-A (2006) Are point counts of boreal songbirds reliable proxies for more intensive abundance estimators? Auk 123:438

Totman CD (1989) The green archipelago: forestry in preindustrial Japan. University of California Press, Berkeley

Tscharntke T, Tylianakis JM, Rand TA, Didham RK, Fahrig L, Batáry P, Bengtsson J, Clough Y, Crist TO, Dormann CF, Ewers RM, Fründ J, Holt RD, Holzschuh A, Klein AM, Kleijn D, Kremen C, Landis DA, Laurance W, Lindenmayer D, Scherber C, Sodhi N, Steffan-Dewenter I, Thies 
C, van der Putten WH, Westphal C (2012) Landscape moderation of biodiversity patterns and processes_eight hypotheses. Biol Rev 87:661-685

Vaccaro AS, Filloy J, Bellocq MI (2019) What land use better preserves taxonomic and functional diversity of birds in a grassland biome? Avian Conserv Ecol 14:1

Villéger S, Mason NWH, Mouillot D (2008) New multidimensional functional diversity indices for a multifaceted framework in functional ecology. Ecology 89:2290-2301

Violle C, Navas M, Vile D, Kazakou E, Fortunel C (2007) Let the concept of trait be functional! Oikos 116:882-892

Watson JEM, Whittaker RJ, Freudenberger D (2005) Bird community responses to habitat fragmentation: how consistent are they across landscapes? J Biogeogr 32(8): 1353-1370

Wickham H (2016) ggplot2: elegant graphics for data analysis. Springer, New York

Wilman H,Belmaker J, Simpson J, de la Rosa Marcelo C, Rivadeneira MM, Jetz W (2014) EltonTraits 1.0: species-level foraging attributes of the world's birds and mammals. Ecology 95:20-27

Yamaura Y, Amano T, Kusumoto Y, Nagata H, Okabe K (2011) Climate and topography drives macroscale biodiversity through land-use change in a human-dominated world. Oikos 120:427-451

Yamaura Y, Kawahara T, Iida S, Ozaki K (2008) Relative importance of the area and shape of patches to the diversity of multiple taxa. Conserv Biol 22:1513-1522

Yamaura Y, Oka H, Taki H, Ozaki K, Tanaka H (2012) Sustainable management of planted landscapes: Lessons from Japan. Biodivers Conserv 21:3107-3129

Yamaura Y, Royle JA (2017) Community distance sampling models allowing for imperfect detection and temporary emigration. Ecosphere 8:e02028

Yoshikawa T, Harasawa S, Isagi Y, Niikura N, Koike S, Taki H, Naoe S, Masaki T (2017) Relative importance of landscape features, stand structural attributes, and fruit availability on fruit-eating birds in Japanese forests fragmented by coniferous plantations. Biol Conserv 209:356-365

Zuur AF, Ieno EN, Elphick CS (2010) A protocol for data exploration to avoid common statistical problems. Methods Ecol Evolut 1:3-14

Publisher's Note Springer Nature remains neutral with regard to jurisdictional claims in published maps and institutional affiliations 